\title{
Role of Proximal Femoral Nail in the Treatment of Unstable Intertrochanteric Fractures
}

\author{
Asad Khan Ghilzai ${ }^{1}$, Syed Kamran Ali Shah*2, Muhammad Ayub Khan ${ }^{3}$, Muhammad Arsalan Ghazi ${ }^{2}$ and \\ Muhammad Kazim Rahim Najjad ${ }^{1}$ \\ ${ }^{1}$ Consultant orthopaedics ,Trauma Orthopaedic Clinic, Pakistan
}

${ }^{2}$ Resident Orthopaedics, Liaquat National Hospital, Pakistan

${ }^{3}$ Senior Registrar Orthopaedic Surgery, Liaquat National Hospital, Pakistan

Received: December 29, 2017; Published: January 09, 2018

*Corresponding author: Dr Syed Kamran Ali Shah, Dept. of Orthopaedics, K-Block, Liaquat, National Hospital, Stadium road, Karachi, Tel: 0322-3077485; Email: drkami1405@gmail.com

\section{Abstract}

Objective: To evaluate the functional outcome of unstable Intertrochanteric fractures treated with proximal femoral nail while using Harris hip score.

Methods: This is a prospective observational study conducted at Orthopaedic Surgery Department. Total 91 patients of either gender with age between 18 to 70 years had closed $\mathrm{AO}$ type $31 \mathrm{~A} 2$ and $31 \mathrm{~A} 3$ unstable Intertorchanteric fractures of proximal femur and for ease labelled as type I and type II subsequently. All patients were operated with proximal Femoral Nail, using a standard prescribed surgical technique. After 3 months of surgery, patient was called for follow up and asked to answer the Harris hip score questionnaire. Effect modifiers were controlled by stratification using chi square test and $p$-value $\leq 0.05$ was considered as significant.

Result: Total 91 patients were enrolled, 59 male and 32 were female. The mean age was $47.66 \pm 13.40$ years, with range of $50(20-70)$ years. $32(35.2 \%)$ patients were aged $\leq 45$ years and $59(64.8 \%)$ patients were aged $>45$ years. $46.2 \%$ patients had type-I fracture and $53.8 \%$ had type-II fracture. Excellent outcome observed in $28.6 \%$ patients, good in $45.1 \%$, fair outcome in $16.5 \%$ and only $9.9 \%$ expressed poor outcome among 91 patients. No significant association of functional outcome observed with respect to gender ( $\mathrm{p}=0.289)$, age ( $\mathrm{p}=0.127)$, type of fracture ( $\mathrm{p}=513)$, and mode of admission ( $\mathrm{p}=0.662)$.

Conclusion: Proximal Femoral Nailing is one of safe and better ways of treating unstable intertrochanteric fractures to achieve significantly better outcomes with early rehabilitation as its advantages of being inserted through small exposure, preservation of hematoma and less blood loss. Hence, we observed in our study the Proximal Femoral Nail may be the better fixation implant for unstable intertrochanteric fractures.

Keywords: Unstable Intertrochanteric Fractures; Proximal Femoral Nail; Harris Hip Score

Abbreviations: IT: Intertrochanteric; PFN: Proximal Femoral Nail; PFNA: Proximal Femoral Nail Anti rotation

\section{Introduction}

Intertrochanteric (IT) fractures are disabling injuries that most commonly affect the elderly population and also in young. The incidence has increased significantly during recent years due to the advancing age of the world's population [1]. The incidence of intertrochanteric fracture is rising because of increasing number of senior citizens with osteoporosis. By 2040 the incidence is estimated to be doubled. In India the figures may be much more [2]. Problems of these fractures are association with substantial morbidity and mortality, malunion, implant failure, cut-out of head, and penetration into hip with great financial burden to the family [2]. Inherently Intertrochanteric fractures composed of anatomically different patterns that vary in their degree of stability following open reduction and internal fixation [3]. The unstable variety constitutes one half of the fracture as described by Evans intertrochanteric fractures classification [4].

With the passage of time and experience has repeatedly emphasized itself that such unstable variety of fractures are not treatable by the standard sliding hip screw used frequently for the stable types [5,6]. In elderly population trochanteric fractures represent a major health risk, although a large number of different implants are available for fixation, the ideal implant for treatment of peritrochanteric fractures is still a matter for discussion. The imperative goals of treatment can be achieved by early mobilization and stable fixation with minimally invasive procedure as possible. Several fixation devices have been developed to overcome the difficulties encountered in the treatment of unstable trochanteric 
femoral fractures. Recently intramedullary fixations devices have become increasingly popular because of its biomechanical advantage, and high rates of failure are debatable in fractures which were treated with sliding hip-screw system device. One implant of such type is the proximal femoral nail (PFN) was developed by the AO/ASIF in 1996 [7], it is commonly used now internationally [8] as well as nationally [9].

Interrochanteric fractures are very frequently faced by orthopaedic surgeons worldwide [10,11]. Increase in the incidence of these fractures are seen 5th decade of life onwards [11,12]. Age of patient, osteoporosis, general health, associated co morbidities are some of the key factors to be considered for the successful treatment of these fractures $[11,13]$. There for surgical treatment is preferred option of treatment as it facilitates early mobilization $\&$ functional recovery [11-17]. But single screw construct was considered unstable for trochanteric fractures which led to introduction of proximal femoral nail in 1997 by AO/ASIF which has provision of two screw placement in the femoral head. This system of Antirotation screw \& cervical load bearing screw in this nail makes this construct biomechanically very stable $[11,13,17,18]$.

The main principle of this type of fixation is based on a sliding screw in the femoral neck-head fragment, attached to an intramedullary nail. Despite being technically difficult to perform, these implants are gaining wide acceptance in treating unstable intertrochanteric fractures because of its advantages of being inserted through small exposure, preservation of hematoma and less blood loss [19,20]. Uzun M et al. [21] evaluated radiographic complications occurring after treatment of unstable intertrochanteric hip fractures with the Proximal Femoral Nail (PFN) and their effect on functional results on 35 patients. The Harris hip score results were excellent in 11 patients (31.4\%), good in 15 patients (42.9\%), and fair in seven patients (20\%). Ye PH et al. [22] investigated the clinical results of the proximal femoral nail antirotation (PFNA) system in the treatment of unstable intertrochanteric femoral fractures in 90 patients. The mean Harris hip score was (80.5 +/-9.8). According to Harris hip scores evaluation system, 26 patients (28\%) reached an excellent result, $37 \operatorname{good}(41 \%), 18$ poor $(20 \%)$.

Sahin S et al. [23] conducted a study Radiographic and functional results of osteosynthesis using the proximal femoral nail antirotation (PFNA) in the treatment of unstable intertrochanteric femoral fractures in 45 patients. The mean Harris hip score was 77.8. Harris hip scores were very good in 11 patients $(24.4 \%)$, good in 19 patients $(42.2 \%)$, moderate in nine patients $(20 \%)$, and poor in six patients (13.3\%). Aim of our study is to evaluate the functional outcome of Proximal Femoral Nail in patients with unstable intertrochanteric fractures. Number of studies has been published nationally and internationally in literature on treatment of these fractures with a dynamic hip screw, but not much has been published on fixation with proximal femoral nail. This study will provide a baseline data and if the results are acceptable it may help to change operative treatment of unstable intertrochanteric femur fractures.

\section{Materials and Methods}

This was a prospective observational study conducted at the Department of Orthopaedic Surgery, Liaquat National Hospital and Medical College, Karachi. March 2015 to Feb 2016. Patients were registered using a predesigned Performa. Approval from institutional ethical review committee was taken prior to commencement of the study. Formal informed written consent was obtained from patients registering in the study. Using a nonprobability, consecutive sampling technique 91 patients were registered for the study.

\section{Inclusion Criteria}
i. Patients aged between 18 yrs and 70yrs
ii. Patients of either sex
iii. Patients with closed fractures
iv. Patients admitted through Accident and Emergency or Outpatients Department with AO type 31A2(type I) and 31A3(type II) intertorchanteric fractures of femur (diagnosed by $\mathrm{X}$ rays)

v. Patients fit to undergo surgical procedure

\section{Exclusion Criteria}

i. Patients with cognitive disorders not able to communicate effectively
ii. Pathological fracture
iii. Open fracture
iv. Any other associated injury

After meeting the inclusion and exclusion criteria, patients were included in the study. Physical and radiological examination was done by principal investigator. All patients were operated using a standard prescribed surgical technique by the experienced surgeon (having greater than 5 yrs experience). Patients have a follow up protocol at $2^{\text {nd }}, 6^{\text {th }}$, and $12^{\text {th }}$ week after operations. After 3 months of surgery, patient was called for follow up and asked to answer the Harris hip score questionnaire. Harris hip score was collected using a pre-designed Performa by the principal investigator. Confounding variables as well as bias was controlled by strictly following the exclusion criteria. Data were entered and analyzed through Statistical Package for Social Sciences (V-17).

Mean and standard deviation were computed for the quantitative variable i.e., age. Frequency and percentage were calculated for qualitative variables like gender, mode of admission, type of fracture, and functional outcome (Excellent to poor). Effect modifiers were controlled by stratification of age, gender, type of fracture and mode of admission to observe the effect of these modifiers on outcome by using chi square test and $p$ value $\leq 0.05$ was considered significant.

\section{Result}

Total 91 patients of either gender with age 18 to 70 years admitted through emergency department with closed fracture 
of AO type 31A2 (type I) and 31A3 (type II) were evaluated to determine the functional outcome of unstable intertrochanteric fractures treated with proximal femoral nail using Harris hip score. Descriptive statistics was calculated. Mean \pm SD were calculated for quantitative variables. Frequency and percentages were calculated for qualitative variables. Stratification was done and post stratification chi square test was used. P-value $\leq 0.05$ was considered as significant. The results showed that there were 59 (64.8\%) male and $32(35.2 \%)$ female patients with mean age were $47.66 \pm 13.40$ years, with range of 50(20-70) years. Age is stratified in two groups and according to stratified groups, $32(35.2 \%)$ patients were aged $\leq 45$ years and $59(64.8 \%)$ patients were aged $>45$ years.

Mean age of patients aged $\leq 45$ years was $31.97 \pm 9.26$ years and for patients aged $>45$ years the mean age was $56.17 \pm 4.83$ years. The results showed that $46.2 \%$ patients had AO type $31 \mathrm{~A} 2$ (type-I) fracture according to AO classification and 53.8\% had AO type 31A3 (type-II) fracture according to the same classification. It was observed that $73(80.2 \%)$ patients were admitted through Emergency department and 18 (19.8\%) patients were admitted throughout patients department. The functional outcome was observed and results showed that excellent outcome was found in $26(28.6 \%)$ patients, good outcome was found in $41(45.1 \%)$ patients, fair outcome was found in $15(16.5 \%)$ patients, and poor outcome was found in 9 (9.9\%) patients (Figures 1-5).

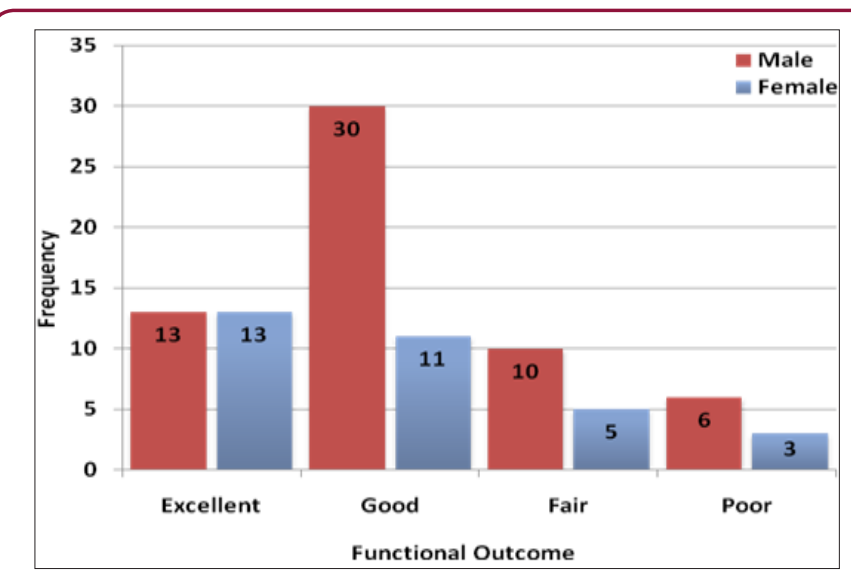

Figure 1: Frequency of functional outcome according to gender $(n=91)$.

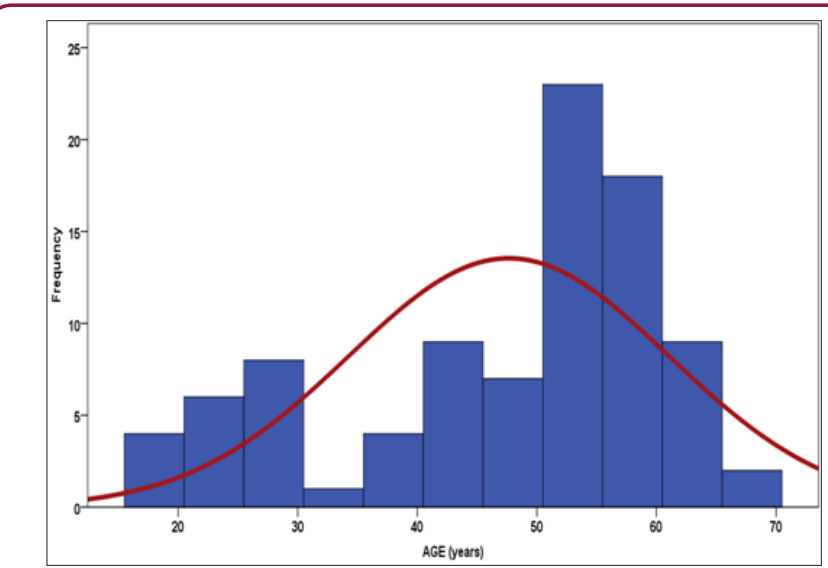

Figure 2: Histogram presenting distribution of age in years $(n=91)$.

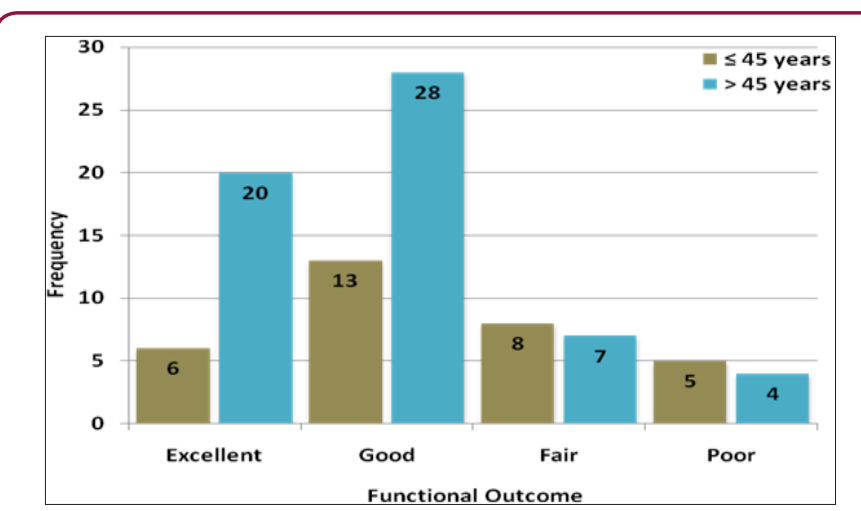

Figure 3: Frequency of functional outcome according to age groups $(n=91)$.

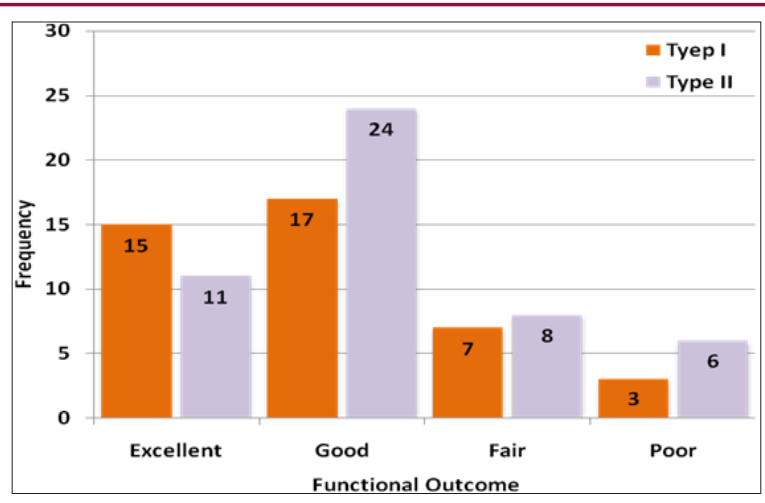

Figure 4: Frequency of functional outcome according to type of fracture $(n=91)$

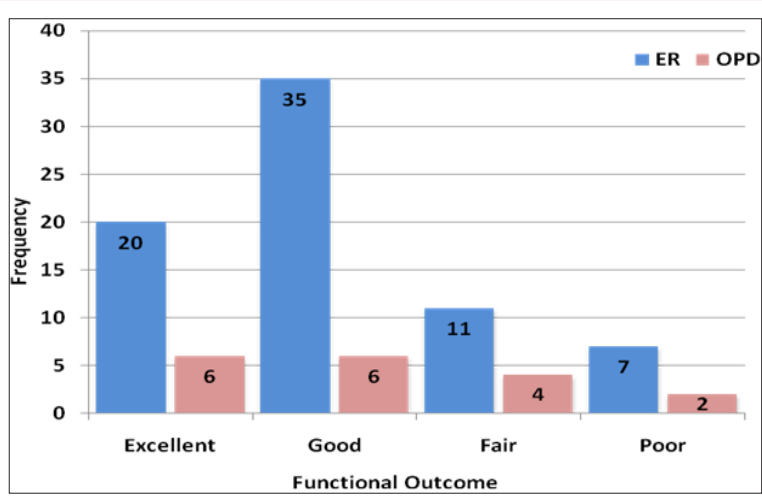

Figure 5: Frequency of functional outcome according to mode of admission $(n=91)$.

Table 1: Frequency Distribution of Functional Outcome (n=91).

\begin{tabular}{|c|c|c|}
\hline & Frequency (n) & Percentage (\%) \\
\hline Excellent & 26 & $28.6 \%$ \\
\hline Good & 41 & $45.1 \%$ \\
\hline Fair & 15 & $16.5 \%$ \\
\hline Poor & 9 & $9.9 \%$ \\
\hline Total & 91 & \\
\hline
\end{tabular}

The Harris hip score was observed according to outcome. Among patients with excellent outcome the mean Harris hip score was $95.77 \pm 3.15$ and in patients with good outcome the mean score was $85.29 \pm 2.90$, similarly among patients with fair outcome the mean Harris hip score was $75.53 \pm 2.80$ and in patients with poor 
outcome the mean score was $65.44 \pm 2.45$. The stratification was done on gender, age, type of fracture and mode of admission. Chi square test was applied considered p-value $\leq 0.05$ as significant (Table 1).

Results showed no significant association of functional outcome was observed with gender $(p=0.289)$, age $(p=0.127)$, type of fracture $(p=513)$, and mode of admission $(p=0.662)$ as $p$ value found statistically insignificant.

\section{Discussion}

Proximal femoral nail is an intramedullary device and has all advantages of intramedullary biomechanics, such as decreasing the moment arm, can be performed by closed technique, which preserve the fracture haematoma and it's an important consideration in fracture healing, it also decrease blood loss, infection risk, minimizes soft tissue dissection and wound related complications [24]. The Proximal Femoral Nail (PFN) System offers some major biomechanical innovations [25]. Axial loading in A1 and A2 fractures leads to fracture impaction, whereas in A3 fractures such impaction doesn't occur, and medial displacement of the distal fragment of the fracture is common due to the instability. Proximal Femoral Nail for A3 type unstable fracture has superior results; PFN has been shown to prevent the fractures of the femoral shaft by having a smaller distal shaft diameter which reduces stress concentration at the tip [26].

Due to its position close to the weight-bearing axis the stress generated on the intramedullary implants is negligible. The PFN implant also acts as a buttress in preventing the mediatisation of the shaft. The entry portal of the PFN through the trochanter limits the surgical insult to the tendinous hip abductor musculature, only unlike those nails which require entry through the pyriformis fossa $[27,28]$. The stabilising and the compression screws of the PFN adequately compress the fracture, leaving between them a bone block for further revision should the need arise [26]. Domingo et al. [29] conducted a study on 295 patients for intertrochanteric fracture fixation with PFN and obtained overall results were comparable with those of other frac $\neg$ ture systems, authors assert that technically surgery is not complex and numbers of recoded complications were acceptable. The intraoperative variables and the systemic complications were similar to those encoun $\neg$ tered by other devices [30,31].

At present, PFN is an acceptable and minimally invasive implant for unstable proximal femoral fractures. Quality of life and function are usually measures that are important for patients and health care provid $\urcorner$ ers [25]. There is ability to perform activities of daily routine like walking, squatting, cross leg sitting, climbing stairs was acceptable in patients of intertrochanteric fracture fixation with PFN [18]. A comparable study was carried out on total of 39 patients for unstable intertrochanteric fractures (AO/OTA 31-A3) were treated with $\mathrm{PFN}$ and $95^{\circ}$ screw-plate with one year follow up. Result reported that patients treated with PFN had shorter operative times, fewer blood transfusions, and shorter hospital stays compared with those treated with a $95^{\circ}$ screw-plate. Also noticed seven of the 19 patients who had been treated with the $95^{\circ}$ screw-plate experienced implant failure and/or non union but in comparison to this only one fracture out of 20 treated with PFN underwent non union [19].

Poor reduction, malrotation or wrong choice of screws results in technically failures of PFN. An intraoperative fracture displacement during manual insertion of the nail into the femoral shaft may be a problem with the PFN, as the entry point of the PFN at the tip of the greater trochanter is located directly in the fracture region which can cause an intra operative fracture displacement [31]. The use of the PFN has become an attractive option now as locally manufactured implant and instruments are available in Pakistan. Because of excellent experience with femoral and tibial inter-lock nailing and our increasing expertise in the technique, we have used the new method of nailing more and more frequently during the last few years. Immediate stability and early bony union vindicated the overall efficacy of the close nailing technique and is in line with another study by Anglen et al. [32] Immediate stability had the concomitant advantage of restoration of full function of the extremity. This was demonstrated by the fact that $68 \%$ of our patients achieved prefracture mobility in the injured limb within six months. This is in line with other studies of the proximal femoral nail and Gamma nail, which reported a restoration of mobility in $40 \%$ to $70 \%$ of patients [33].

It would seem that the improvementin mobility can be attributed to improved restoration of hip anatomy and biomechanics achieved by this new implant. Studies comparing the DHS with the PFN also found that patients who received a nail were $50 \%$ more mobile than those with a DHS, which had best results before AO/Asif PFN [9]. Our findings regarding mobility are in line with these studies. At present, we consider that the PFN is a good minimally invasive implant when closed reduction is possible. The modification of the PFN and careful surgical technique should reduce the high complication rate in our study.

\section{Conclusion}

From our experience with the Proximal Femoral Nail, it was observed that although the method is technically demanding and requires special instrumentation, but the advantage of immediate stability in difficult and unstable fractures, and the relatively few complications serve to recommend it for the method of choice for surgical treatment of unstable intertrochanteric femoral fractures. The intramedullary nail provided significantly lower rates of implant failure and delayed healing, thereby lessening the need for revision surgery. We conclude that in unstable intertrochanteric fractures the PFN has significantly better outcomes in terms of earlier restoration of walking ability as its advantages of being inserted through small exposure, preservation of hematoma and less blood loss. In our opinion, PFN may be the better fixation device for most intertrochanteric fracture.

\section{References}

1. Dhamangaonkar AC (2015) Management Options and Treatment Algorithm in Intertrochanteric Fractures. Int Trauma 1(1): 12-16.

2. Kulkarni GS, Limaye R, Kulkarni M, Kulkarni S (2006) Intertrochanteric fractures. Indian J Orthop 40: 16-23. 
3. Whitelaw GP, Segal D, Sanzone CF, Ober NS, Hadley N (1990) Unstable intertrochanteric/subtrochanteric fractures of the femur. Clin Orthop 252: 238-245.

4. Evans EM (1949) The treatment of trochanteric fractures of the femur. J Bone Joint Surg Br 31B(2): 190-203.

5. Haidukewych GJ, Israel TA, Berry DJ (2011) Reverse obliquity fractures of the intertrochanteric region of the femur. J Bone Joint Surg Am 83A(5): 643-650.

6. Broos PL, Rommens PM, Deleyn PR, Geens VR, Stappaerts KH (1991) Pertrochanteric fractures in the elderly: are there indications for primary prosthetic replacement? J Orthop Trauma 5(4): 446-451.

7. Simmermacher RKJ, Bosch AM, Van der Werken C (1993) The AO ASIFproximal femoral nail (PFN): a new device for treatment of unstable proximal femoral fractures. Injury 30(5): 327-332.

8. Gadegone WM, Salphale YS (2007) Proximal femoral nail-an analysis of 100 cases of proximal femoral fractures with an average follow up of 1 year. Int Orthop 31(3): 403-418.

9. Babar IU, Qureshi AR, Afsar SS (2011) An experience of the treatment of unstable inter-trochanteric fractures with the AO/ASIF proximal femoral nail. J Postgrad Med Inst 25(3): 267-271.

10. Wasudeo M Gadegone, Yogesh S Salphale (2010) Short proximal femoral nail fixation for trochanteric fractures. J Orthopaed Surg 18(1): 39-44.

11. Yadkikar SV, Yadkikar VS (2015) Prospective study of proximal femoral nail in management of trochanteric and subtrochanteric fractures of femur. Int J Biomed Adv Res 6(4): 349-54.

12. Ballmer FT, Ballmer PM, BF, Ganz R, Mast JW (1990) Pauwels osteotomy for nonunions of the femoral neck. Orthop Clin North Am 21(4): 759767.

13. Gadegone WM, Salphale YS (2010) Short proximal femoral nail fixation for trochanteric fractures. J Orthopaed Surg 18(1): 39-44.

14. Ansari Moein CM, Verhofstad MHJ, Bleys RLAW, van der Werken C (2005) Soft tissue injury related to the choice of entry point in ante grade femoral nailing; pyriform fossa or greater trochanter tip. J Clin Orthop Injury 36(11): 1337-1342.

15. Banan H, Al-Sabti A, Jimulia T, Hart AJ (2002) The treatment of unstable, extracapsular hip fractures with the AO/ASIF proximal femoral nail (PFN) our first 60 cases. Injury 33(5): 401-405.

16. Brumback RJ, Uwagie-Ero S, Lakatos RP, Poka A, Bathon GH, et al. (1988) Intramedullary nailing of femoral shaft fractures. Part II: Fracturehealing with static interlocking fixation. J Bone Joint Surg 70: 1453-1462.

17. Wasudeo GM, Yogesh SS (2010) Short proximal femoral nail fixation for trochanteric fractures. J Orthopaed Surg 18(1): 39-44.

18. Shriniwas YV, Vishnu YS, Mayank P, Gandhi D, Rahul K (2015) Outcome of intertrochanteric fractures treated with short femoral nail. Int J Med Res Health Sci 4(3): 646-651.

19. Sadowski C, Lubbeke A, Saudan M, Riand N, Stern R, et al. (2002) Treatment of reverse oblique and transverse intertrochanteric fractures with use of an intramedullary nail or a 95 degrees screw-plate: a prospective, randomized study. J Bone Joint Surg 84: 372-381.
20. Elis J, Chechik O, Maman E, Steinberg EL (2012) Expandable proximal femoral nails versus $95^{\circ}$ dynamic condylar screw-plates for the treatment of reverse oblique intertrochanteric fractures. Injury 43(8): 1313-1317.

21. Uzun M, Ertürer E, Ozturk I, Akman S, Seçkin F, et al. (2009) [Longterm radiographic complications following treatment of unstable intertrochanteric femoral fractures with the proximal femoral nail and effects on functional results]. Acta Orthop Traumatol Turc 43(6): 457463.

22. Ye PH, Huang L, Zha NF, He XF, Ruan YP, et al. (2011) Proximal femoral nail for the treatment of unstable intertrochanteric femoral fractures. Zhongguo Gu Shang 24(8): 645-647.

23. Sahin S, Ertürer E, Ozturk I, Toker S, Seçkin F, et al. (2010) Radiographic and functional results of osteosynthesis using the proximal femoral nail antirotation (PFNA) in the treatment of unstable intertrochanteric femoral fractures. Acta Orthop Traumatol Turc 44(2): 127-134.

24. Kalliguddi S, Jawali V, Reneesh UP (2013) Proximal femoral nail in the mangement of peritrochanteric fractures femur and its functional outcome. Int J Res Pharm Biomed Sci 4(4): 1276-1286.

25. Korkmaz MF, Erdem MN, Disli Z, Selcuk EB, Karakaplan M, et al. (2014) Outcomes of trochanteric femoral fractures treated with proximal femoral nail: an analysis of 100 consecutive cases. Clin Interv Aging 9: 569.

26. Gadegone WM, Salphale YS (2007) Proximal femoral nail-an analysis of 100 cases of proximal femoral fractures with an average follow up of 1 year. Int Orthop 31: 403-408.

27. Menezes DF, Gamulin A, Noesberger B (2005) Is the proximal bfemoral nail a suitable implant for treatment of all trochanteric fractures? Clin Orthop Relat Res 439: 221-227.

28. Ansari Moein CM, Verhofstad MHJ, Bleys RLAW, van der Werken C (2005) Soft tissue injury related to the choice of entry point in ante grade femoral nailing; pyriform fossa or greater trochanter tip. Injury 36: $1337-1342$.

29. Domingo LJ, Cecilia D, Herrera A, Resines C (2001) Trochanteric fractures treated with a proximal femoral nail. Int Orthop 25(5): 298-301.

30. Simmermacher RK, Bosch AM, Van der Werken C (1999) The AO/ASIFproximal femoral nail (PFN): a new device for the treatment of unstable proximal femoral fractures. Injury 30(5): 327-332.

31. Simmermacher RK, Ljungqvist J, Bail H (2008) AO - PFNA study group. The new proximal femoral nail antirotation (PFNA) in daily practice: results of a multicentre clinical study. Injury 39(8): 932-939.

32. Anglen JU, Weinstein JN (2008) Nail or plate fixation of inter-trochanteric fractures: changing pattern of practice. A review of the American Board of Orthopaedic Surgery database. J Bone Joint Surg Am 90(4): 700-717.

33. Al-Yassari G, Langstaff RJ, Jones JWM, Al-Lami M (2002) The AO/ASIF proximal femoral nail (PFN) for the treatment of unstable femoral fracture. Injury 33: 395-399.

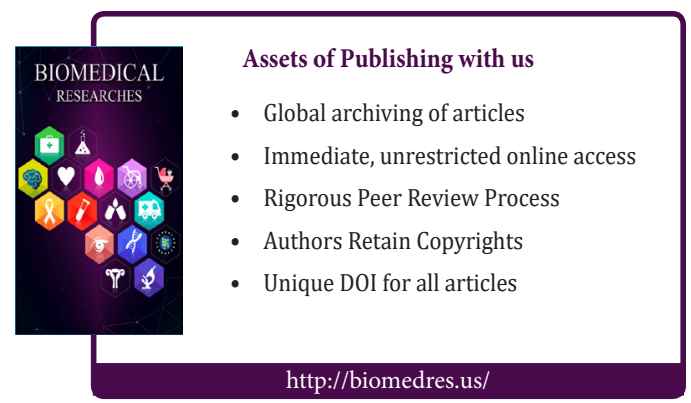

